\title{
The Analysis of Food Intake in Patients with Cirrhosis Waiting for Liver Transplantation: A Neglected Step in the Nutritional Assessment
}

\author{
Francesco Palmese ${ }^{1}$, Ilaria Bolondi ${ }^{1}$, Ferdinando Antonino Giannone ${ }^{2}$, Giacomo Zaccherini ${ }^{1}$ (1), \\ Manuel Tufoni ${ }^{1}$, Maurizio Baldassarre ${ }^{1,3}$ and Paolo Caraceni ${ }^{1,3, *}$ \\ 1 Department of Medical and Surgical Sciences, Alma Mater Studiorum University of Bologna, \\ 40138 Bologna, Italy; palmesefrancesco@gmail.com (F.P.); ilaria_bolondi@yahoo.it (I.B.); \\ g.zaccherini@gmail.com (G.Z.); manuel.tufoni@gmail.com (M.T.); baldassarre.maurizio@gmail.com (M.B.) \\ 2 Support Services and People Care, General Direction, S. Orsola-Malpighi University Hospital, \\ 40138 Bologna, Italy; ferdinando.giannone@gmail.com \\ 3 Centre for Applied Biomedical Research (C.R.B.A.), Alma Mater Studiorum University of Bologna, \\ 40138 Bologna, Italy \\ * Correspondence: paolo.caraceni@unibo.it; Tel.: +39-051-2142919; Fax: +39-051-2142930
}

Received: 26 August 2019; Accepted: 9 October 2019; Published: 15 October 2019

\begin{abstract}
Patients with cirrhosis waiting for liver transplantation (LT) frequently present a nutritional disorder, which represents an independent predictor of morbidity and mortality before and after transplantation. Thus, a proper assessment of the food intake by using different methods, such as food records, food frequency questionnaires, and $24 \mathrm{~h}$ recall, should be deemed an important step of the nutritional management of these patients. The available published studies indicate that the daily food intake is inadequate in the majority of waitlisted patients. These findings were confirmed by our experience, showing that the daily intake of total calories, proteins and carbohydrates was inadequate in approximately $85-95 \%$ of patients, while that of lipids and simple carbohydrates was inadequate in almost $50 \%$ of them. These data highlight the need to implement an effective educational program provided by certified nutritionists or dieticians, who should work in close collaboration with the hepatologist to provide a nutritional intervention tailored to the individual patient requirements.
\end{abstract}

Keywords: malnutrition; cirrhosis; liver transplantation; food records; caloric intake; macronutrients intakes; patient adherence

\section{Introduction}

Patients with end-stage cirrhosis waiting for liver transplantation (LT) are frequently malnourished, showing different nutritional disorders, e.g., undernutrition, sarcopenia and obesity, which may also coexist in the same patient [1,2]. Besides the intuitive association between undernutrition and sarcopenia, the prevalence of sarcopenic obesity is increasing over the last years due to the growing number of patients with cirrhosis caused by non-alcoholic steatohepatitis (NASH) [3-6]. Although a wide variability of diagnostic methods used, among studies the prevalence of nutritional disorders results usually high (up to 75\%) [2]. Instead, there is a worldwide accepted consensus that malnutrition represents an independent predictor of morbidity and mortality in patients with cirrhosis before and after LT $[1,7]$.

In a systematic review, it has been observed that both severe under nutrition (BMI $<18.5 \mathrm{~kg} / \mathrm{m}^{2}$ ) and severe obesity (BMI $>40 \mathrm{~kg} / \mathrm{m}^{2}$ ) in patients undergoing liver transplantation are associated with increased mortality and complications [8]. Obesity, diabetes and familiarity for diabetes are independent risk factors for the development of metabolic syndrome after liver transplantation, which 
is associated with a higher risk of cardiovascular complications, malignancy and poor outcome $[9,10]$. On the other hand, patients with pre-operative malnutrition undergoing liver transplantation have higher mortality, susceptibility to infections, longer hospital stay (both intensive care unit and regular ward) after liver transplantation [11,12]. Moreover, very low protein intake in patients awaiting liver transplantation is associated with malnutrition and mortality [13]. There are no conclusive formal trials showing that preoperative nutritional intervention improves clinical outcome [1], but it is not surprising that in recent years, a growing emphasis has been placed on the importance of nutrition in the global management of patients with cirrhosis and, more specifically, in candidates for LT. To this effect, recommendations regarding the amount, type and distribution of dietary macro- and micro-nutrients as well as the assessment and diagnosis of nutritional disorders in patients with cirrhosis have been recently published by several international and national scientific societies $[1,14,15]$. A brief general synthesis of these indications is shown in Table 1.

Table 1. General nutritional recommendations for patients with cirrhosis.

\begin{tabular}{cc}
\hline Nutritional Recommendations & \\
\hline Energy & $35 \mathrm{kcal} / \mathrm{kg}$ body weight ${ }^{1}$ \\
Protein & $1.2-1.5 \mathrm{~g} / \mathrm{kg}$ body weight ${ }^{2}$ \\
Total Carbohydrates & $45-75 \%$ of caloric intake \\
Simple Carbohydrates & $10-15 \%$ of caloric intake \\
Fibers & $25-45 \mathrm{~g} /$ daily \\
Lipids & $20-30 \%$ of caloric intake \\
Special Considerations & \\
Hepatic Encephalopathy & Increase BCAAs and decrease ammonia intake \\
Ascites & Fluid restriction and low-sodium intake $(<2$ g/day) \\
\hline Actual body weight if BMI $<25$, actual body weight-500/850 kcal if BMI $\geq 25$, dry body weight in patients \\
presenting fluid retention [1]. ${ }^{2}$ Actual body weight if BMI $<25$, ideal body weight if BMI $\geq 25$, dry body weight in \\
patients presenting fluid retention [1]. Abbreviations: BCAA: branched chain amino acid, BMI: body mass index.
\end{tabular}

As a result, many transplant hepatologists are currently including a screening for nutritional disorders as a part of their regular clinical work-up. Among the screening tools for the risk of malnutrition, the Royal Free Hospital—Global Assessment and the Royal Free Hospital-Prioritizing Tool have been validated in patients with cirrhosis [16]. Furthermore, due to its clearly established strong negative impact on patient's frailty and pre- and post-transplant outcomes [17], the use of screening tools for sarcopenia (i.e., hand-grip strength test, $4 \mathrm{~m}$ walking test, chair standing test, $6 \mathrm{~min}$ walking test, etc.) and its objective quantification with imaging techniques (computed tomography (CT) or magnetic resonance (MR)) is spreading in clinical practice [17].

Once a nutritional disorder or at least a condition of high risk has been demonstrated, the analysis of the current dietary habits would be particularly useful in order to unveil the discrepancies with the established nutritional recommendations and to effectively improve patient adherence to them. Unfortunately, this step is often neglected.

\section{The Assessment of Food Intake}

Several tools have been developed to assess food intake, including the Food Records (FRs), the Food Frequency Questionnaire (FFQ), and the $24 \mathrm{~h}$ recall $(24 \mathrm{hR})$ [18]. There is still an open debate on which tool can be considered the most accurate due to the limitations related to misreporting, technical reproducibility and the availability of resources [19-22]. Main advantages and disadvantages of each tool are resumed in Table 2. 
Table 2. Main advantages and disadvantages of methods to assess food intake.

\begin{tabular}{|c|c|c|}
\hline & Advantages & Disadvantages \\
\hline $\begin{array}{c}\text { Food } \\
\text { Records }\end{array}$ & $\begin{array}{l}\text { Detailed information on the } \\
\text { actual food intake at the time } \\
\text { of recording. } \\
\text { Absence of recall bias since the } \\
\text { diary should be filled in at the } \\
\text { time of food consumption. } \\
\text { Interviewer not required to } \\
\text { collect information. }\end{array}$ & $\begin{array}{l}\text { - All participants need to be highly motivated and } \\
\text { literate to properly fill in all the fields of the diary, } \\
\text { thus excluding some groups of patients or limiting } \\
\text { the accuracy of their report. In order to overcome } \\
\text { this limitation, some devices, including voice } \\
\text { records, food atlas, camera and mobile phones, can } \\
\text { be also used. } \\
\text { - Time-consuming method. } \\
\text { Participants could modify their dietary intake } \\
\text { during their recording days. }\end{array}$ \\
\hline $\begin{array}{c}24 \mathrm{~h} \\
\text { Recall }\end{array}$ & $\begin{array}{l}\text { - Short time required. } \\
\text { - Applicable in large studies } \\
\text { including patients with } \\
\text { different ethnicity. } \\
\text { - No literacy required. } \\
\text { - No influence on the eating habits. }\end{array}$ & $\begin{array}{l}\text { - Relies on the memory of the participants. } \\
\text { - } \quad \text { Trained interviewers are required. } \\
\text { - A single test may not be representative of the real } \\
\text { patient's eating habit. Thus, to account for } \\
\text { day-to-day variations, the } 24 \text { h recall }(24 \mathrm{hR}) \text { should } \\
\text { be repeated several times [1]. }\end{array}$ \\
\hline FFQ & $\begin{array}{l}\text { - } \quad \text { Relatively low-cost method. } \\
\text { - Short time required, especially } \\
\text { when self-administered. } \\
\text { Easier data management since in } \\
\text { most cases it is pre-coded. } \\
\text { - A large population can } \\
\text { be investigated. }\end{array}$ & $\begin{array}{l}\text { - It relies on the long-term memory of the } \\
\text { participants, referring to several weeks. } \\
\text { Quantification of portions could be inaccurate. } \\
\text { It is not an open-ended method, so some foods } \\
\text { could not be reported if they are not in the list of } \\
\text { available items. }\end{array}$ \\
\hline
\end{tabular}

\subsection{The Food Records}

FRs are prospective, open-ended survey methods to collect data about food and beverage intake during a certain period. They consist of a self-recording of foods and drinks at the time they are consumed. It is important to train the participants on how to properly report their meals, including information about the location, time, type of food consumed, different ingredients and methods of preparation, portions or weights, and product labels when available. Although a weight record is the most accurate way to correctly quantify the nutritional intake, the portion sizes can be also quantified with the help of a photographic model or standard household measures and then converted by the interviewer in weight [23]. A length of 3 days is the minimum time required to record reliable data on food consumption. Longer times (i.e., 7 days) increase the amount of information and reduce the day-to-day variability, but it has been shown that periods of over four consecutive days are associated with a lower accuracy of the records. Thus, short FRs are more often used and the diary can be filled in non-consecutive days (both weekend and working days) with the aim to collect more representative information of the different dietary habits of the week. The diary is analyzed by trained researchers, also with the possibility of using software programs specifically developed for this purpose, which are equipped with images of food portions and can be used to directly estimate the average daily caloric intake and the percentages of macronutrients [23].

The latest guidelines of the European Association for the Study of the Liver indicate the FRs as the preferred method to assess food intake in patients with cirrhosis, even if in the absence of strong supporting evidence [1].

\subsection{The $24 \mathrm{~h}$ Recall}

The $24 \mathrm{~h}$ recall $(24 \mathrm{hR})$ is an open-ended retrospective method to investigate dietary intake. It consists of an interview carried out by a trained investigator about all the food and beverages 
consumed during all the preceding day. It may be computer-assisted and requires the interviewer to be familiar with all the available foods, methods of preparation and the nutritional habits of the population in exam [24].

\subsection{The Food Frequency Questionnaire}

The FFQ is a retrospective, not open-ended method to investigate dietary intake. It allows the assessment of the frequency of consumption of pre-listed foods and beverages during a certain period (usually weeks). Since the items are pre-determined, the choice of the foods and beverages available in the list should be tailored to the population being examined, taking into account the characteristics and the eating habits of the participants. Moreover, the questionnaire should investigate portion sizes to better quantify dietary intake [24].

\section{Studies Focused on Food Intake in Patients Awaiting LT}

We performed an accurate search based on the following Medical Subject Heading (MeSH) keywords: "Food records", "liver transplantation", "food diaries", "caloric intake", "protein intake", "liver cirrhosis". The databases used for the search were: Scopus (www.scopus.com) (1969-2019), MEDLINE (1969-2019), and the US National Library of Medicine (www.PubMed.gov) (to find the 'in process' citations missed by MEDLINE). The references of the studies were used to find additional articles. The screening of titles and abstracts was performed by two authors (F.P. and I.B.). Full-length versions of selected articles were then assessed for inclusion criteria: studies in patients aged $>18$ years; cirrhosis defined on histopathologic, laboratory, clinical and ultrasound features; studies performed on outpatient; paper published in the English language. The following data were collected: number of patients; tool used for the analysis of the nutritional intake; total energy intake; carbohydrates daily intake; protein daily intake; lipids daily intake (Table 3).

Table 3. Analysis of the nutritional intake in patients with cirrhosis waiting for liver transplantation in published studies.

\begin{tabular}{ccccccc}
\hline Authors & $\boldsymbol{n}$ & Tool & $\begin{array}{c}\text { Total Energy Intake } \\
\text { (kcal/Day) }\end{array}$ & $\begin{array}{c}\text { Carbohydrates } \\
\text { (g) }\end{array}$ & $\begin{array}{c}\text { Protein } \\
\text { (g) }\end{array}$ & $\begin{array}{c}\text { Lipids } \\
\text { (g) }\end{array}$ \\
\hline Ferreira et al. [25] & 17 & 3d-FR & $1670.5 \pm 489.8^{*}$ & 236.5 & 72.9 & 48.2 \\
\hline Lunati et al. [12] & 84 & $3 \mathrm{~d}-\mathrm{FR}$ & $2006 \pm 624^{*}$ & 285.9 & 75.2 & 62.4 \\
\hline Brito-Costa et al. [26] & 56 & $24 \mathrm{hR}$ & $2062.8 \pm 797.8^{*}$ & 259.4 & 94.9 & 71.5 \\
\hline Mc Coy et al. [11] & 17 & $7 \mathrm{~d}-\mathrm{FR}$ & $2257.2 \pm 605.9^{*}$ & 281 & 132.6 & 73 \\
\hline Merli et al. [27] & 25 & $\ddagger$ & $2030(1610-2870)^{\dagger}$ & - & 63 & - \\
\hline Marr et al. [28] & 70 & $3 \mathrm{~d}-\mathrm{FR}$ & $1766.4^{*}$ & - & - & - \\
\hline Andrade et al. [29] & 23 & $24 \mathrm{hR}$ & $1774.3 \pm 537.9^{*}$ & 234.5 & 93.6 & 53.9 \\
\hline Ney et al. [13] & 630 & $2 \mathrm{~d}-\mathrm{FR}+\mathrm{FFQ}$ & - & - & 68.8 & - \\
\hline Ferreira et al. [30] & 73 & $3 \mathrm{~d}-\mathrm{FR}$ & $1485.1(559.3-3432)$ & 218.1 & 60.5 & 42.8 \\
\hline Merli et al. [9] & 38 & $\ddagger$ & $2006 \pm 423^{*}$ & - & - & - \\
\hline Ferreira et al. [31] & 16 & $3 \mathrm{~d}-\mathrm{FR}$ & $1520(576-2713.6)$ & - & - & - \\
\hline Richardson et al. [32] & 23 & $3 \mathrm{~d}-\mathrm{FR}$ & $1542 \pm 124^{*}$ & 199 & 60.3 & 62.3 \\
\hline Ferreira et al. [33] & 159 & $24 \mathrm{hR}$ & $1490.9 \pm 580.7^{*}$ & 225.7 & 56 & 36.7 \\
\hline
\end{tabular}

Abbreviations: 3d-FR: three-days food records; $24 \mathrm{hR}$ : twenty-four hour recall; 7d-FR: seven-days food records; FFQ: food frequency questionnaire; 2d-FR: two-days food records; - not found in the article; * the mean \pm standard deviation. ${ }^{\dagger}$ the median range. $\ddagger$ interviews and analysis performed with the use of specific software (WinFood, Medimatica, Colonnella Teramo, Italy). 
It has to be acknowledged that the above cited studies in waitlisted patients were not exclusively focused on the analysis of the dietary intake, which was instead part of a more extensive nutritional assessment often designed to evaluate the changes occurring after LT. Thus, not all the studies reported the daily intake of all macronutrients [9,13,27,28,31] or total calories [13], while, for other studies $[9,28,30]$, we calculated the average daily intakes from the values reported for the different patients' sub-groups.

The common finding emerging from these studies, which were performed in different areas of the world, is that the majority of patients with cirrhosis awaiting LT presented a state of malnutrition associated with inadequate dietary intakes. In particular, caloric and protein intake was frequently deficient in malnourished patients $[9,13,27,28,30,33]$. However, even not malnourished patients at the initial assessment had inadequate nutritional intakes that were well below the level of adequacy, in particular regarding caloric and protein intakes [13,28,30,33], but also regarding total carbohydrates and lipids [33]. The cohorts of these studies were heterogeneous and the percentage of patients with inadequate caloric intake ranged from $13.1 \%$ (data derived from the weighted average) [28] to 91.8\% [30] among different study populations. Moreover, some patients reported an excess of caloric and protein intake [11].

We have recently performed an observational prospective study specifically designed to assess the food intake in a cohort of outpatients with cirrhosis at different stages of severity [34]. The EmiliaRomagna ethic committee (CE-AVEC) reviewed and approved the study (number of approval 33/2014/U/Sper) and all patients gave informed consent before the inclusion. The analysis of the 3d-FR showed unequivocally that these patients have an inadequate, usually deficient, intake of calories and macronutrients, thus presenting poor adherence to the current guidelines even if they received general nutritional recommendations by the attending hepatologist during the normal path of care.

For the purpose of this review, we have repeated the analysis including only the 33 patients who were in the waiting list for LT at the time of the study, including patients with non-advanced hepatocellular carcinoma (HCC) within the Milan criteria. Food intake was calculated by the 3d-FR according to the nutritional tables of products or referring to the Food Composition Database for Epidemiological Studies in Italy [35]. To determine the degree of adherence, the average daily intake of each patient was compared to what is recommended by the latest nutritional guidelines [1]. In case of fluid retention, the dry body weight was estimated in three different ways: (1) referring to a weight registered before the fluid retention, (2) referring to a post-paracentesis body weight or (3) by subtracting a percentage $(5,10$ or $15 \%$ in relation of the degree of liquid retention) [1]. Each parameter was considered appropriate if it was within the reference range indicated by the nutritional recommendations [1]. Finally, we calculated the degree of inadequacy in terms of distance from the reference range.

Patients were predominantly male $(86 \%)$, with a median age of $57.1 \pm 5.99$ years and a mean BMI of $27.5 \pm 4.5$. Nine patients $(27 \%)$ were in Child-Pugh class A, $20(61 \%)$ in class B and four $(12 \%)$ in class C. HCC was present in 14 patients $(42 \%)$. As expected, prognostic scores were higher in patients without HCC as compared to those with HCC (Child-Pugh: $8.6 \pm 1.8$ vs. $6.8 \pm 1.5$; Model for End stage Liver Disease (MELD): $17.4 \pm 2.7$ vs. $11.6 \pm 3.5$ ).

As shown in Table 4, the analysis of the 3d-FR has demonstrated a level of adequacy equal to $58 \%$ and $61 \%$ for the daily consumption of lipids and simple carbohydrates, respectively. Instead, a completely different picture has emerged regarding the intakes of calories, protein, and complex carbohydrates, with a clear majority of patients presenting an insufficient intake (79-94\%).

We also analyzed the number and distribution of meals, considering both main meals and snacks. Only 17 patients (52\%) had at least four meals per day, which was considered the threshold to define the adequate the number of daily meals. Moreover, a late-night snack was eaten by 11 out the 17 patients $(65 \%)$ having at least four meals per day. In contrast, none of the 16 patients without a sufficient number of daily meals declared eating a late-night snack. Finally, only $27 \%$ of patients self-reported any physical activity. 
No statistically significant difference emerged among patients grouped according the Child-Pugh classes in terms of inadequacy of macronutrients intake and eating patterns, likely as a result of the low sample size, particularly in the Child-Pugh C group.

Table 4. Patient adherence to nutritional intake according to international nutritional guidelines $(n=$ 33).

\begin{tabular}{cccc}
\hline Energy and Macronutrients Intake & Adequate & Inadequate Reduced & Inadequate Excessive \\
\hline Total energy intake & $5(15 \%)$ & $26(79 \%)$ & $2(6 \%)$ \\
\hline Protein intake & $3(9 \%)$ & $29(88 \%)$ & $1(3 \%)$ \\
\hline Complex carbohydrates intake & $2(6 \%)$ & $31(94 \%)$ & $0(0 \%)$ \\
\hline Lipids intake & $19(58 \%)$ & $12(36 \%)$ & $2(6 \%)$ \\
\hline Simple carbohydrate intake & $20(61 \%)$ & $9(27 \%)$ & $4(12 \%)$ \\
\hline
\end{tabular}

Each parameters was considered appropriate if included within the reference range indicated by the guidelines [1].

As shown in Figure 1, when the study population was divided according to the tertiles of inadequacy, the distribution of patients appeared to be homogeneous among the tertiles. Moreover, a considerable number of patients had a nutritional intake far from the level of adequacy. As an example, over $50 \%$ of patients with insufficient caloric intake presented a deficit higher than $800 \mathrm{kcal} / \mathrm{day}$.

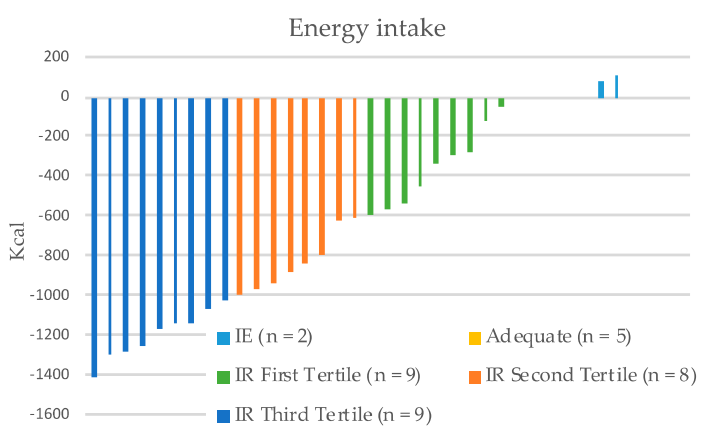

(a)

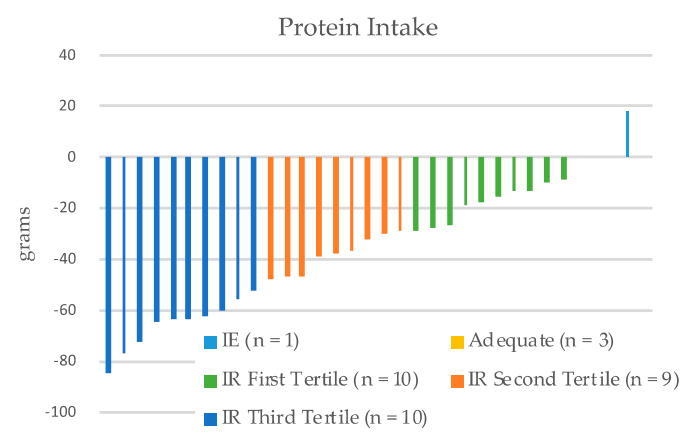

(c)

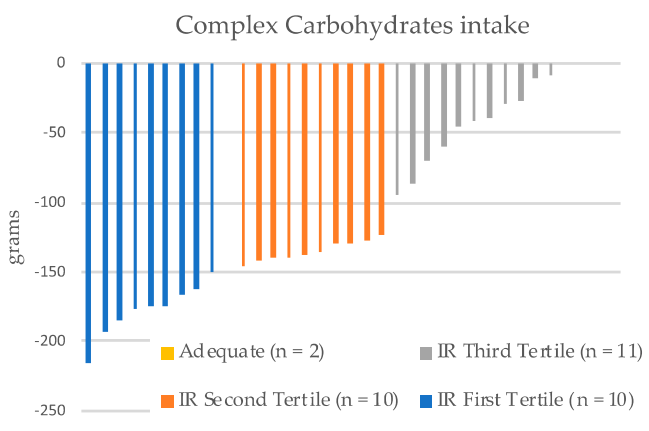

(b)

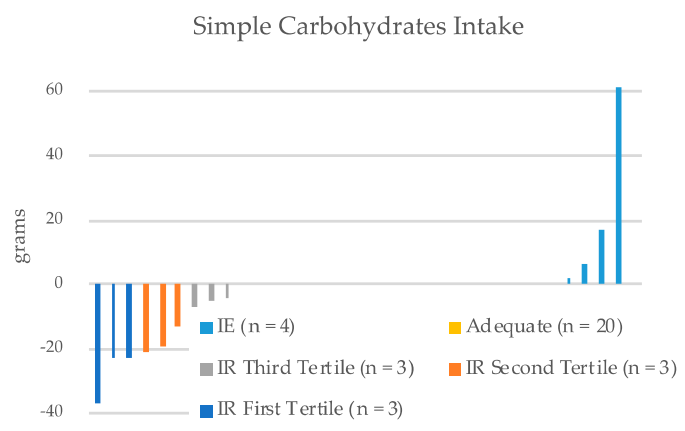

(d)

Figure 1. Cont. 


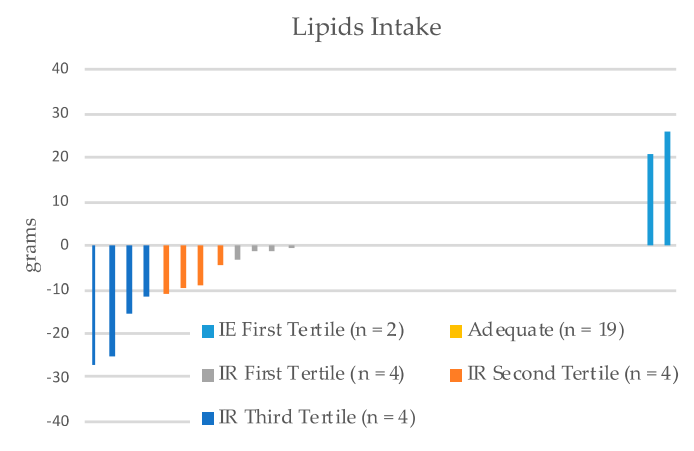

(e)

Figure 1. Degree of inadequacy for each macronutrient intake from the normal ranges indicated by international guidelines. The distribution of the degree of inadequacy from the range of normal intake is shown in the tertiles $(n=33)$. (a) Energy intake; (b) Complex carbohydrates intake; (c) Protein intake;

(d) Simple carbohydrates intake; (e) Lipids intake. IR: inadequate reduced. IE: inadequate in excess.

Finally, it is worth of mentioning that waitlisted patients presented a much higher willingness to complete the FRs as compared to those observed in patients with cirrhosis not listed for LT (33/40 $(82.5 \%)$ vs. $45 / 121(37.2 \%))$. In summary, our data are consistent with the findings of the studies mentioned above, in particular regarding the inadequacy of nutritional intake.

\section{Discussion}

The major finding emerging from the studies assessing the food intake in patients waiting for LT is represented by the low-level adherence to the nutritional recommendations provided by the current international guidelines [1]. This result raises two important questions.

The first question is: why is the diet of these patients so far from what is recommended? There are several reasons to explain this finding: poor knowledge of patients and physicians on the composition of food and drinks, family environment and low socio-economic conditions, low consciousness of the key role of nutrition for the management of the disease that leads to general poor compliance with prescribed diets, or not enough time to provide nutritional recommendation in the daily clinical practice $[2,13]$. Interestingly, the common wisdom that "fat and sweet" food consumption is a damaging habit may have contributed to the higher adherence observed for lipid and simple carbohydrate intake.

The second question is: how can we improve the food intake of these patients? In most cases according to the regular planned path of care, the physician provides patients with general advice on liquid and food consumption with the support of simple written material. The results available highlight that this approach is not sufficient and there is a need to implement an educational program provided by certified nutritionists or dieticians. The high motivation usually observed in patients waiting for LT may also favor their compliance to a nutritional program. Interestingly, in our analysis, the proportion of patients accepting the nutritional evaluation was significantly higher in waitlisted patients as compared to candidates for LT.

Despite the possibility that HCC could have been a confounding factor in our study, in the 14 patients with non-advanced HCC, the burden of active tumor was quite limited and they presented better liver function compared to patients without HCC.

A close collaboration between hepatologists and nutritionists is warranted since the nutritional requirements of patients with end-stage cirrhosis can greatly change due to many complications of the disease, such as ascites, hepatic encephalopathy, renal failure, and diabetes. In fact, some of the interventions needed to manage these complications can have a negative impact on the nutritional balance of these patients [36]. As examples, sarcopenia can be worsened by the low-protein diet prescribed to prevent the recurrence of hepatic encephalopathy [5], or the adoption of a low-sodium diet in order to manage ascites can make food less palatable, leading to a further reduction in 
caloric intake [36]. Thus, the nutritional intervention should be tailored to the specific needs of the individual patient.

\section{Conclusions}

Patients with cirrhosis waiting for LT present a very low adherence to recommendations provided by the international nutritional guidelines. Due to the poor prognostic impact of nutritional disorders on mortality and morbidities before and after LT, the assessment of the daily food intake, within the frame of a global evaluation of nutritional status, should be part of the management of these patients. Moreover, any nutritional intervention should be the result of a multidisciplinary approach involving both hepatologists and nutritionists and tailored to the specific needs of each patient.

Author Contributions: Conceptualization F.P., I.B., F.A.G., P.C.; data collection F.P., I.B., F.A.G.; data analysis F.P., I.B., M.B., manuscript preparation F.P., I.B., G.Z., M.T., P.C.; critical review all authors. All authors have approved the final version of the article.

Funding: This research received no external funding.

Conflicts of Interest: The authors declare no conflict of interest.

\section{References}

1. European Association for the Study of the Liver. EASL clinical practice guidelines on nutrition in chronic liver disease. J. Hepatol. 2019, 70, 172-193. [CrossRef] [PubMed]

2. Burra, P.; Giannini, E.G.; Caraceni, P.; Ginanni Corradini, S.; Rendina, M.; Volpes, R.; Toniutto, P. Specific issues concerning the management of patients on the waiting list and after liver transplantation. Liver Int. 2018, 38, 1338-1362. [CrossRef] [PubMed]

3. Zamboni, M.; Mazzali, G.; Fantin, F.; Rossi, A.; Di Francesco, V. Sarcopenic obesity: A new category of obesity in the elderly. Nutr. Metab. Cardiovasc. Dis. 2008, 18, 388-395. [CrossRef] [PubMed]

4. Montano-Loza, A.J.; Angulo, P.; Meza-Junco, J.; Prado, C.M.; Sawyer, M.B.; Beaumont, C.; Esfandiari, N.; Ma, M.; Baracos, V.E. Sarcopenic obesity and myosteatosis are associated with higher mortality in patients with cirrhosis. J. Cachexia Sarcopenia Muscle 2016, 7, 126-135. [CrossRef]

5. Amodio, P.; Bemeur, C.; Butterworth, R.; Cordoba, J.; Kato, A.; Montagnese, S.; Uribe, M.; Vilstrup, H.; Morgan, M.Y. The nutritional management of hepatic encephalopathy in patients with cirrhosis: International society for hepatic encephalopathy and nitrogen metabolism consensus. Hepatology 2013, 58, 325-336. [CrossRef]

6. Norman, K.; Kirchner, H.; Lochs, H.; Pirlich, M. Malnutrition affects quality of life in gastroenterology patients. World J. Gastroenterol. 2006, 12, 3380-3385. [CrossRef]

7. Zhu, J.; Zhang, Z.; Zhang, H.; Zhang, M.; Qiu, M.; Yuan, W. Italian multicentre cooperative project on nutrition in liver cirrhosis. Nutritional status in cirrhosis. J. Hepatol. 1994, 21, 317-325. [CrossRef]

8. Kamath, P.S.; Wiesner, R.H.; Malinchoc, M.; Kremers, W.; Terry, M.; Therneau, T.M.; Kosberg, C.L.; D'Amico, G.; Dickson, E.R.; Kim, W.R. A model to predict survival in patients with end-stage liver disease. Hepatology 2001, 33, 464-470. [CrossRef]

9. Merli, M.; Giusto, M.; Gentili, F.; Novelli, G.; Ferretti, G.; Riggio, O.; Corradini, S.G.; Siciliano, M.; Farcomeni, A.; Attili, A.F.; et al. Nutritional status: Its influence on the outcome of patients undergoing liver transplantation. Liver Int. 2010, 30, 208-214. [CrossRef]

10. Harrison, J.; McKiernan, J.; Neuberger, J.M. A prospective study on the effect of recipient nutritional status on outcome in liver transplantation. Transpl. Int. 1997, 10, 369-374. [CrossRef]

11. McCoy, S.M.; Campbell, K.L.; Lassemillante, A.-C.M.; Wallen, M.P.; Fawcett, J.; Jarrett, M.; Macdonald, G.A.; Hickman, I.J. Changes in dietary patterns and body composition within 12 months of liver transplantation. Hepatobiliary Surg. Nutr. 2017, 6, 317-326. [CrossRef] [PubMed]

12. Lunati, M.E.; Grancini, V.; Agnelli, F.; Gattic, S.; Masserinia, B.; Zimbalattia, D.; Pugliesed, G.; Rossic, G.; Donatob, M.F.; Colombob, M.; et al. Metabolic syndrome after liver transplantation: Short-term prevalence and pre- and post-operative risk factors. Dig. Liver Dis. 2013, 45, 833-839. [CrossRef] [PubMed] 
13. Ney, M.; Gramlich, L.; Mathiesen, V.; Bailey, R.J.; Haykowsky, M.; Ma, M.; Abraldes, J.G.; Tandon, P. Patient-perceived barriers to lifestyle interventions in cirrhosis. Saudi J. Gastroenterol. 2017, 23, 97-104. [CrossRef] [PubMed]

14. Plauth, M.; Bernal, W.; Dasarathy, S.; Merli, M.; Plank, L.D.; Schütz, T.; Bischoff, S.C. ESPEN guideline on clinical nutrition in liver disease. Clin. Nutr. 2019, 38, 485-521. [CrossRef] [PubMed]

15. Bémeur, C.; Butterworth, R.F. Reprint of: Nutrition in the management of Cirrhosis and its neurological complications. J. Clin. Exp. Hepatol. 2015, 5, S131-S140. [CrossRef]

16. Borhofen, S.M.; Gerner, C.; Lehmann, J.; Fimmers, R.; Görtzen, J.; Hey, B.; Geiser, F.; Strassburg, C.P.; Trebicka, J. The royal free hospital-nutritional prioritizing tool is an independent predictor of deterioration of liver function and survival in Cirrhosis. Dig. Dis. Sci. 2016, 61, 1735-1743. [CrossRef]

17. Cruz-Jentoft, A.J.; Baeyens, J.P.; Bauer, J.M.; Boirie, Y.; Cederholm, T.; Landi, F.; Martin, F.C.; Michel, J.-P.; Rolland, Y.; Schneider, S.M. Sarcopenia: European consensus on definition and diagnosis. Age Ageing 2010, 39, 412-423. [CrossRef]

18. García-Rodríguez, M.T.; López-Calviño, B.; Piñon-Villar, M.D.C.; Otero-Ferreiro, A.; Suárez-López, F.; Gómez-Gutiérrez, M.; Pértega-Díaz, S.; Seoane-Pillado, M.T.; Pita-Fernández, S. Concordance among methods of nutritional assessment in patients included on the waiting list for liver transplantation. J. Epidemiol. 2017, 27, 469-475. [CrossRef]

19. Poslusna, K.; Ruprich, J.; de Vries, J.H.M.; Jakubikova, M.; van't Veer, P. Misreporting of energy and micronutrient intake estimated by food records and 24 hour recalls, control and adjustment methods in practice. Br. J. Nutr. 2009, 101, S73-S85. [CrossRef]

20. Yang, Y.J.; Kim, M.K.; Hwang, S.H.; Ahn, Y.; Shim, J.E.; Kim, D.H. Relative validities of 3-day food records and the food frequency questionnaire. Nutr. Res. Pract. 2010, 4, 142. [CrossRef]

21. De Keyzer, W.; Huybrechts, I.; De Vriendt, V.; Vandevijvere, S.; Slimani, N.; Van Oyen, H.; De Henauw, S. Repeated 24-hour recalls versus dietary records for estimating nutrient intakes in a national food consumption survey. Food Nutr. Res. 2011, 55. [CrossRef] [PubMed]

22. Talegawkar, S.A.; Tanaka, T.; Maras, J.E.; Ferrucci, L.; Tucker, K.L. Validation of nutrient intake estimates derived using a semi-quantitative FFQ against 3 day diet records in the Baltimore Longitudinal Study of Aging. J. Nutr. Health Aging 2015, 19, 994-1002. [CrossRef] [PubMed]

23. Ortega, R.M.; Perez-Rodrigo, C.; Lopez-Sobaler, A.M. Dietary assessment methods: Dietary records. Nutr. Hosp. 2015, 31, 38-45. [CrossRef] [PubMed]

24. Amorim Cruz, J.A. Selection of methodology to assess food intake. Eur. J. Clin. Nutr. 2002, 56, S25-S32. [CrossRef]

25. Ferreira, L.G.; Santos, L.F.; Anastácio, L.R.; Lima, A.S.; Correia, M.I.T.D. Resting energy expenditure, body composition, and dietary intake. Transplantation 2013, 96, 579-585. [CrossRef]

26. Brito-Costa, A.; Pereira-Da-Silva, L.; Papoila, A.L.; Alves, M.; Mateus, É.; Nolasco, F.; Barroso, E. Factors associated with changes in body composition shortly after orthotopic liver transplantation: The potential influence of immunosuppressive agents. Transplantation 2016, 100, 1714-1722. [CrossRef]

27. Merli, M.; Giusto, M.; Riggio, O.; Gentili, F.; Molinaro, A.; Francesco Attili, A.; Ginanni Corradini, S.; Rossi, M. Improvement of nutritional status in malnourished cirrhotic patients one year after liver transplantation. e-SPEN 2011, 6, e142-e147. [CrossRef]

28. Marr, K.J.; Shaheen, A.A.; Lam, L.; Stapleton, M.; Burak, K.; Raman, M. Nutritional status and the performance of multiple bedside tools for nutrition assessment among patients waiting for liver transplantation: A Canadian experience. Clin. Nutr. ESPEN 2017, 17, 68-74. [CrossRef]

29. Andrade, C.P.R.; Portugal, M.L.T.; de Sousa Paz, E.; Freitas, P.A.; Daltro, A.F.C.S.; Almondes, K.G.S.; Maia, C.S.C.; Oliveira, A.C. Influence of liver transplantation in the nutritional profile of severe cirrhotic patients. Nutr. Hosp. 2018, 35, 104-109. [CrossRef]

30. Ferreira, L.G.; Ferreira Martins, A.I.; Cunha, C.E.; Anastácio, L.R.; Lima, A.S.; Correia, M.I.T.D. Negative energy balance secondary to inadequate dietary intake of patients on the waiting list for liver transplantation. Nutrition 2013, 29, 1252-1258. [CrossRef]

31. Ferreira, L.G.; Santos, L.F.; Silva, T.R.; Anastácio, L.R.; Lima, A.S.; Correia, M.I.T.D. Hyper- and hypometabolism are not related to nutritional status of patients on the waiting list for liver transplantation. Clin. Nutr. 2014, 33, 754-760. [CrossRef] [PubMed] 
32. Richardson, R.A.; Garden, O.J.; Davidson, H.I. Reduction in energy expenditure after liver transplantation. Nutrition 2001, 17, 585-589. [CrossRef]

33. Ferreira, L.G.; Anastácio, L.R.; Lima, A.S.; Correia, M.I.T.D. Malnutrition and inadequate food intake of patients in the waiting list for liver transplant. Rev. Assoc. Med. Bras. 2009, 55, 389-393. [CrossRef] [PubMed]

34. Palmese, F.; Giannone, F.A.; Bolondi, I.; Baldassarre, M.; Zaccherini, G.; Tufoni, M.; Boffelli, S.; Berardi, S.; Trevisani, F.; Caraceni, P. Low adherence to nutritional recommendations in patients with Cirrhosis: A prospective observational study. J. Gastroenterol. Hepatol. Res. 2019, 8, 2896-2902. [CrossRef]

35. Gnagnarella, P.; Salvini, S.; Parpinel, M. Food Composition Database for Epidemiological Studies in Italy. Available online: http://www.bda-ieo.it/ (accessed on 15 May 2019).

36. Tsiaousi, E.T.; Hatzitolios, A.I.; Trygonis, S.K.; Savopoulos, C.G. Malnutrition in end stage liver disease: Recommendations and nutritional support. J. Gastroenterol. Hepatol. 2008, 23, 527-533. [CrossRef]

(C) 2019 by the authors. Licensee MDPI, Basel, Switzerland. This article is an open access article distributed under the terms and conditions of the Creative Commons Attribution (CC BY) license (http://creativecommons.org/licenses/by/4.0/). 